\title{
Binderless zeolite monoliths production with sacrificial biopolymers
}

\author{
Shane Lawson ${ }^{\text {a }}$, Kyle Newport ${ }^{\mathrm{a}}$, Qasim Al-Naddaf ${ }^{\mathrm{a}}$, Alechine E. Ameh ${ }^{\mathrm{b}}$, Ali A. Rownaghi ${ }^{\mathrm{a}}$, \\ Leslie F. Petrik ${ }^{\mathrm{b}}$, Fateme Rezaei ${ }^{\mathrm{a}, *, 1}$ \\ ${ }^{a}$ Department of Chemical \& Biochemical Engineering, Missouri University of Science and Technology, Rolla, MO 65409-1230, United States \\ ${ }^{\mathrm{b}}$ Environmental and Nano Research Group, Department of Chemistry, University of Western Cape, Robert Sobuke Rd, Belleville, Cape Town 7535, South Africa
}

\section{A R T I C L E I N F O}

\section{Keywords:}

3D printing

Binderless monolith

Zeolite

Adsorption

\begin{abstract}
A B S T R A C T
3D printing has emerged as an attractive way of formulating structured adsorbents, as it imparts lower manufacturing costs compared to hydraulic extrusion while also allowing for unprecedented geometric control. However, binderless structures have not been fabricated by 3D printing, as ink formulation has previously required clay binders which cannot be easily removed. In this study, we report the development of a facile approach to shape engineer binderless zeolites. 3D-printed inks comprised of 13X, 5A, ZSM-5, and experimental South African zeolites were prepared using gelatin and pectin as binding agents along with dropwise addition of various solvents. After printing, the dried monoliths were calcined to remove the biopolymers and form $100 \%$ pure zeolite structures. From $\mathrm{N}_{2}$ physisorption and $\mathrm{CO}_{2}$ adsorption measurements at $0{ }^{\circ} \mathrm{C}$, all monoliths showed narrowing below $1 \mathrm{~nm}$ from their powders, which was attributed to pore malformation caused by intraparticle bridging during calcination. The various adsorption isotherms indicated that this narrowing led to varying degrees of enhanced adsorption capacities for all three gases, as the slightly smaller pores increased electrostatic binding between the sorbent walls and captured species. Analysis of $\mathrm{CO}_{2}$ adsorption performance revealed comparable diffusivities and adsorption capacities to the commercial bead analogues, implying that biopolymer/ zeolite printing can produce contactors which are competitive to commercial benchmarks. The binderless monoliths also exhibited faster diffusivities compared to zeolite monoliths produced by conventional direct ink writing - on account of an enhancement in macroporosity - highlighting that this new method enhances the kinetic properties of 3D-printed scaffolds. As such, the sacrificial biopolymer technique is an effective and versatile approach for 3D printing binderless zeolite structures.
\end{abstract}

\section{Introduction}

Zeolites are an important material class, as their high number of active sites and unique pore structures allow them to be used in many industrial processes including adsorption, separation, and catalysis [1-6]. Traditionally, zeolitic structuring has been performed via pellitization or extrusion processes, however, these techniques require adhesion to an inert binder, which reduces the overall support loading and deactivates its pores $[7,8]$. One way to address this problem has been through manufacturing of so-called binderless zeolites by way of hydraulic extrusion, however, this technique still necessitates a small amount of binding agent (i.e., bentonite, kaolinite, etc.), which limits the zeolite loading to less than $100 \mathrm{wt} \%$ [9,10]. Moreover, manufacturing zeolitic structures - either with or without binder - by extrusion necessitates the production of molds to fit different process columns, thereby driving up manufacturing, labor, and machining expenses whenever a new geometry is needed. As such, there have been many efforts in recent years to move away from hydraulic extrusion to allow for greater geometric versatility and reduced manufacturing costs.

An important alternative to traditional manufacturing, 3D printing technology - which digitally tunes the scaffold geometry prior to its formulation with AutoCAD or some equivalent - has cemented itself as a facile way of producing ceramic contactors containing various supports, including metals/metal oxides, metal-organic frameworks (MOFs), and zeolites [1,11-18]. In a pioneering work in 2016 [1], our group formulated zeolite $13 \mathrm{X}$ and $5 \mathrm{~A}$ monoliths with $90 \mathrm{wt} \%$ loading by binding the commercial powders to bentonite clay through 3D printing technique. More recently, Wang et al. [19] surpassed the $90 \mathrm{wt} \%$ threshold by solvothermally bridging commercial zeolite particles, colloidal silica, and halloysite nanotubes after printing to form $100 \%$

\footnotetext{
* Corresponding author.

E-mail address: rezaeif@mst.edu (F. Rezaei).

1 ORCID: 0000-0002-4214-4235.
} 
binderless NaX zeolite monoliths. Nevertheless, although this technique did produce a binderless zeolite structure through 3D printing, the solvothermal step was time-intensive and required extensive optimization to coordinate the various components. Furthermore, this route only produced a single binderless zeolite and, to the best of our knowledge, has never been applied to other families. As such, a versatile and rapid method of 3D printing binderless zeolite structures remains an elusive and important area of additive manufacturing research.

Notably, 3D printing of binderless zeolite monoliths is an especially difficult prospect because, as far as we are aware, formulating a rheologically favorable ink requires some sort of binding agent. Otherwise, directly printing the crystalline particulate leads to expulsion of the dispersion solvent or gives rise to spreading behavior which is incapable of producing a self-standing scaffold. Therefore, simply eliminating binder use cannot be considered a worthwhile or realistic pathway for 3D printing zeolite structures of any family. Nevertheless, binderless printing might still be possible by eliminating the inert species after the formulation step. Granted, accomplishing this with traditional ink additives would likely necessitate some degree of chemical etching to extract the silica-based clays (bentonite, kaolin, etc.) and would inevitably degrade the zeolites as well, since anything reactive enough to dissolve the inert binders would also decompose aluminosilicates. As an alternative, binding agents which can be removed by gentler techniques, such as calcination, should be considered when developing a binderless zeolite printing method, since such a process would give rise to the desired rheological behavior while also allowing for $100 \%$ purity in the final product. This being the case, it is inevitable that this approach's success would heavily depend on the binder properties, meaning that the selection criteria and binder choice are crucial.

When considering previously unexplored binding agents for the development of binderless zeolite printing, there are a few criteria which must be met to ensure a rheologically favorable ink and manufacture a mechanically stable scaffold with large loadings. Namely, the sacrificial binding agents should (i) impart sufficient adhesion with the zeolite particles during ink production to prevent solvent expulsion, (ii) be completely organic so that they can be extracted using calcination, (iii) produce a shear-thinning ink without solvent expulsion, and (iv) exhibit self-standing behavior with geometric stability after deposition. In that regard, we hypothesized that a combination of gelatin and pectin biopolymers would meet these criteria, as such additives degrade well below the zeolitic sintering temperature of $500{ }^{\circ} \mathrm{C}$, are known to impart desirable rheological properties (i.e., self-standing, shear-thinning, hydrophilic, etc.), and have been used to 3D-print nanocellulose, $\mathrm{CaCl}_{2}$, and plant tissue scaffolds [20-25]. Granted, these biopolymers have not yet been used to 3D-print ceramics, however, based on their effectiveness for multiple other supports, we speculated that they would be worth exploring in zeolite ink production and subsequent development of binderless structures. Motivated by this exciting possibility, we embarked on a study which developed a versatile means of 3D-printing binderless zeolite structures using so-called "sacrificial biopolymers" for the first time.

In this proof-of-concept study, we manufactured binderless monoliths using four different zeolites - zeolite 13X, zeolite 5A, H-ZSM-5, and an experimental South African zeolite synthesized from fly ash and provided by Petrik's group $[26,27]$ - by implementing pectin and gelatin as sacrificial binding agents. We also manufactured zeolite $13 \mathrm{X}$ monoliths with small concentrations of bentonite clay (1-5 wt\%), to enhance their mechanical strength, since the $100 \%$ pure zeolite monoliths were somewhat brittle. These samples are noted as $13 \mathrm{X}^{1 \%}, 13 \mathrm{X}^{2.5 \%}$, and $13 \mathrm{X}^{5 \%}$, respectively. Here, it should be noted that we selected the monolithic geometry as to demonstrate this technique because of its relevance in industrial processes and because of its use in previous works for 3D printing $[1,16,19] . \mathrm{CO}_{2}, \mathrm{CH}_{4}$, and $\mathrm{N}_{2}$ adsorption isotherms were collected at $25^{\circ} \mathrm{C}$ from 0 to 1 bar for the calcinated monoliths and parent powders, to demonstrate any differences between adsorption capacities, where the $\mathrm{CO}_{2} / \mathrm{CH}_{4}$ and $\mathrm{CO}_{2} / \mathrm{N}_{2}$ selectivities were calculated by the previously-detailed ideal adsorption solution theory (IAST) method [28]. Lastly, fractional adsorption uptakes were performed on the calcinated zeolite 13X monoliths and commercial beads as well as the calcined 5A monolith and commercial beads to investigate the binderless monoliths' mass transfer properties relative to benchmark sorbents. Overall, the work detailed here establishes a groundbreaking way to 3D-print binderless zeolites of any family through gelation with sacrificial biopolymers and unlocks new pathways in additive manufacturing.

\section{Experimental}

\subsection{Materials}

The following materials were purchased from Sigma Aldrich and were used without modification for the production of binderless zeolite monoliths by 3D printing: gelatin from porcine skin (gel strength $=300$ ), pectin from citrus peel (74\% dried basis), poly(vinyl) alcohol (PVA), methylcellulose (99\%), N-N-dimethylformamide (DMF, ACS), and ethanol (EtOH, ACS). Zeolite 13X and Zeolite 5A were purchased from UOP while $\mathrm{H}-\mathrm{ZSM}-5\left(\mathrm{Al}_{2} \mathrm{O}_{3} / \mathrm{SiO}_{2}=50\right)$ was purchased from Zeolyst. The South African (SA) zeolite was provided by Petrik et al. and was synthesized from fly ash with their established method [26,27]. The binderless zeolite $13 \mathrm{X}$ beads used in the dynamic adsorption experiments were provided by Ingevity, while the zeolite $5 \mathrm{~A}$ beads were provided by Sylobead. All UHP gases were purchased from Airgas.

\subsection{Monolith formulation}

The component fractions and solvent ratios from Table 1 were used to form the printing pastes, as shown in Fig. 1. To form the paste, the powdered components were all added to a PTFE cup at room temperature. Then, the appropriate solvent mixtures were added to the paste in a dropwise fashion to produce a printable rheology. To produce uniformity, the solvents were added dropwise in $\sim 1 \mathrm{~mL}$ increments and the paste was folded together with a spatula until the desired rheological properties (i.e. pliable, self-standing, homogeneous, and non-flow) were observed. Here, it should be noted that - while the gelatin/pectin/ zeolite ratios varied across crystallites - it was generally found that higher pectin/gelatin ratios produced better rheological properties, whereas adding too much gelatin led to shear thickening behavior. As such, when applying this approach to other zeolites, a good starting point for paste optimization would be to begin using only pectin, followed by incremental gelatin addition to minimize ink spreading. It is also worth noting here that, in our earlier techniques $[1,11-16]$, the paste formulation and densification processes took place over the course of 1-3 days, whereas this new technique yielded a printable paste in less than 5 min, meaning that this new method allows for much faster rheological optimization. Therefore, utilizing sacrificial biopolymers for zeolite gelation and 3D printing can be considered a superior technique from a rapid manufacturing perspective, as it dramatically reduced binding time from traditional paste formulation.

After producing the zeolite/biopolymer inks, the monoliths were 3Dprinted using our established setup [1,11-16]. The zeolite $13 \mathrm{X}$ and $5 \mathrm{~A}$ monoliths were printed using $0.84 \mathrm{~mm}$ (Nordson) tips, however, the ZSM-5 and South African monoliths were printed using $1.36 \mathrm{~mm}$ tips because those inks displayed denser rheologies and could not be extruded through the smaller bores. Nevertheless, because the ZSM-5 and South African samples were successfully formed into monoliths, they are still worth discussing here as a proof-of-concept. In subsequent works, we will further tune the paste compositions to enhance geometric and rheological control. After 3D printing, all monoliths were dried overnight in the fume hood $\left(12 \mathrm{~h}, 25{ }^{\circ} \mathrm{C}\right)$ to gently remove the solvents and prevent cracking. Thereafter, they were calcined using a stepwise ramp. In the first step, the monoliths were heated to $350^{\circ} \mathrm{C}$ using a ramp rate of $2{ }^{\circ} \mathrm{C} / \mathrm{min}$ and held isothermally for $2 \mathrm{~h}$. Then, the monoliths were 
Table 1

Paste compositions used to 3D-print binderless zeolite monoliths.

\begin{tabular}{|c|c|c|c|c|c|c|c|c|c|}
\hline Monolith & Zeolite (wt.\%) & Pectin (wt.\%) & Gelatin (wt.\%) & PVA (wt.\%) & Bentonite (wt.\%) & Methyl-cellulose (wt.\%) & DI (mL) & DMF (mL) & EtOH $(\mathrm{mL})$ \\
\hline $13 \mathrm{X}$ & 66.7 & 13.3 & 20.0 & 0.0 & 0.0 & 0.0 & 5 & 1.5 & 0 \\
\hline $13 \mathrm{X}^{1 \%}$ & 66.2 & 13.2 & 19.8 & 0.0 & 0.6 & 0.0 & 5 & 1.5 & 0 \\
\hline $13 X^{2.5 \%}$ & 65.6 & 13.1 & 19.7 & 0.0 & 1.6 & 0.0 & 5 & 1.5 & 0 \\
\hline $13 X^{5 \%}$ & 64.5 & 12.9 & 19.4 & 0.0 & 3.2 & 0.0 & 2.5 & 2.5 & 0 \\
\hline 13X-R4 [1] & 90 & 0 & 0 & 1.0 & 7.0 & 2.0 & 10 & 0 & 0 \\
\hline $5 \mathrm{~A}$ & 92.1 & 2.9 & 5.0 & 0.0 & 0.0 & 0.0 & 5 & 0 & 0 \\
\hline 5A-R4 [1] & 90 & 0 & 0 & 1.0 & 7.0 & 2.0 & 10 & 0 & 0 \\
\hline ZSM-5 & 75.0 & 25.0 & 0.0 & 0.0 & 0.0 & 0.0 & 2.5 & 2.5 & 0 \\
\hline South African & 81.6 & 18.4 & 0.0 & 0.0 & 0.0 & 0.0 & 2.5 & 0 & 2.5 \\
\hline
\end{tabular}

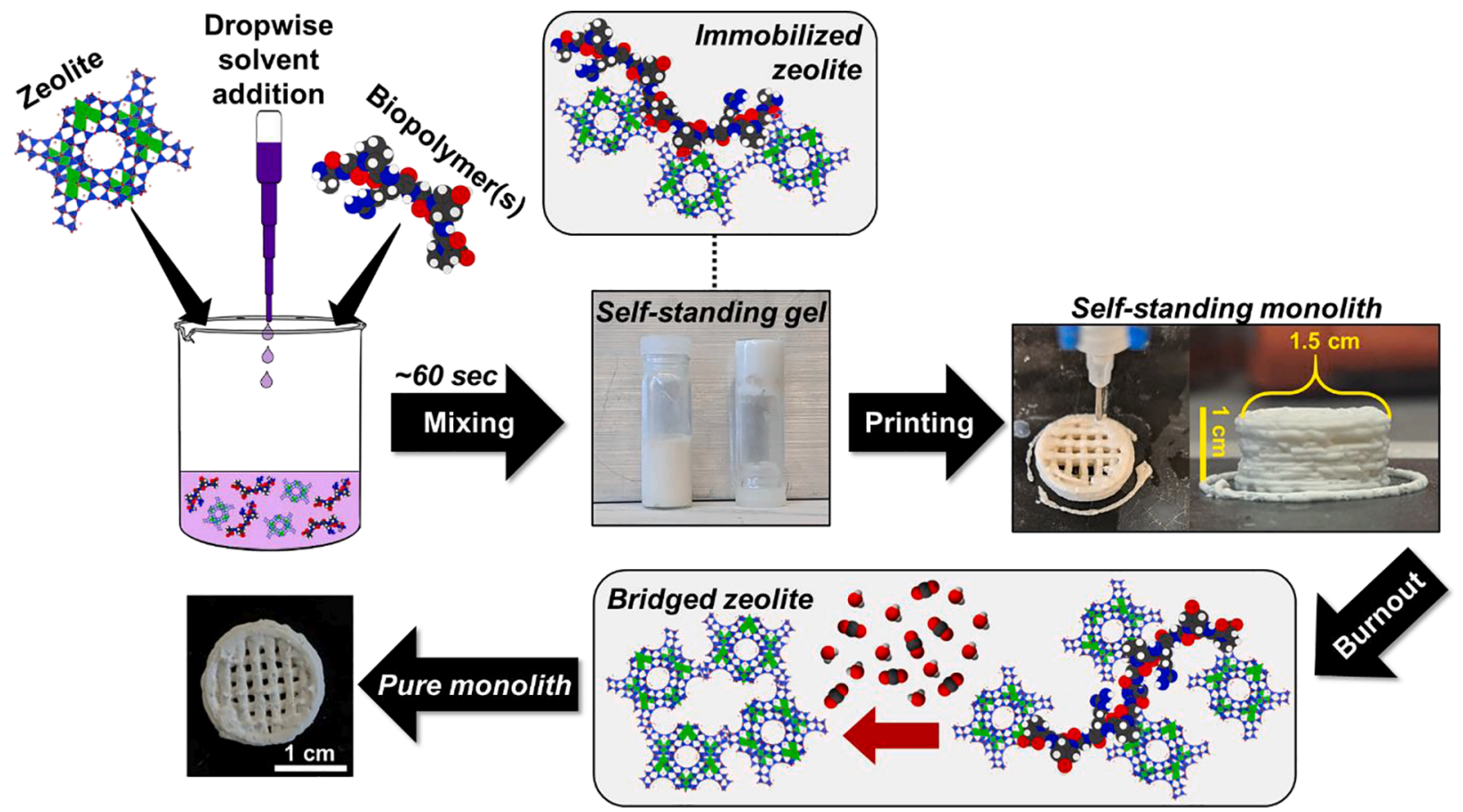

Fig. 1. Schematic representation of binderless zeolite monolith formulation by 3D printing with sacrificial biopolymers.

heated at $2{ }^{\circ} \mathrm{C} / \mathrm{min}$ to $550{ }^{\circ} \mathrm{C}$ for final sintering, where the temperature was held for $6 \mathrm{~h}$. The furnace was then allowed to cool to $25^{\circ} \mathrm{C}$ naturally for $12 \mathrm{~h}$. This stepwise ramp was found to be necessary as rapidly heating the monoliths directly to $550{ }^{\circ} \mathrm{C}$ led to structural decomposition, on account of overly rapid binder burnout. Lastly, it should be noted here that - to compare the kinetic performance of the monoliths produced by this new method to those manufactured by conventional bentonite/zeolite direct ink writing - we also synthesized the 200 cell per square inch (cpsi) 13X-R4 and 5A-R4 monoliths using the technique reported previously. These inks' ratios are also contained in Table 1 and the printing process can be found in our earlier work [1].

\subsection{Material characterization}

To assess the biopolymer degradation temperatures, thermalgravimetric analysis (TGA) was performed on a Q500 TGA (TA Instruments). Therein, the samples were heated at $10{ }^{\circ} \mathrm{C} / \mathrm{min}$ under 60 $\mathrm{mL} / \mathrm{min}$ air from 25 to $900{ }^{\circ} \mathrm{C}$. Both the weight and derivative weight profiles were collected to assess the biopolymers' thermal decompositions. The crystallinity of powdered, uncalcined, and calcined samples were assessed by X-Ray diffraction (XRD) on a PANalytical X'Pert Multipurpose X-ray Diffractometer with a scan step size of $0.02^{\circ}$ / step and a rate of $147.4 \mathrm{~s} / \mathrm{step}$. The monoliths' surface topographies particle binding behaviors were assessed after calcination using a Hitachi S4700 field-emission scanning electron microscope (FE-SEM).
The mechanical strengths of the zeolite $13 \mathrm{X}, 13 \mathrm{X}^{1 \%}, 13 \mathrm{X}^{2.5 \%}$, and zeolite $13 \mathrm{X}^{5 \%}$ monoliths were assessed by an Instron 5881 extensometer under $0.2 \mathrm{~mm} / \mathrm{min}$ compression, anvil height of $5 \mathrm{~mm}$, and a head thickness and width of $2 \mathrm{~mm}$. $\mathrm{N}_{2}$ physisorption isotherm measurements were collected for the zeolite powders, uncalcinated, and calcinated monoliths at $77 \mathrm{~K}$ using a Micromeritics (3Flex) gas analyzer to investigate the samples' textural properties at various stages of manufacturing. Prior to measurement, the samples were degassed under vacuum at $350{ }^{\circ} \mathrm{C}$ on a Micromeritics Smart VacPrep for $6 \mathrm{~h}$ to remove any pre-adsorbed species. The binder-containing (uncalcined) monoliths were degassed at $200{ }^{\circ} \mathrm{C}$ for $6 \mathrm{~h}$ to prevent decomposition of the gelatin and pectin. The surface area and pore size distributions (PSD) were calculated by Brunauer-Emmett-Teller (BET) and nonlocal density functional theory (NLDFT) methods, respectively, from the $\mathrm{N}_{2}$ physisorption data. 3Flex was also used to assess the micropore distributions for the calcined monoliths and parent powders from 0.3 to $1 \mathrm{~nm}$. To accomplish this, the samples were first degassed using the same conditions and underwent isothermal $\mathrm{CO}_{2}$ adsorption from 0 to 1 bar at $0{ }^{\circ} \mathrm{C}$, where the temperature was held by submerging the sample tubes in a well-insulated ice bath. After collecting the data, the adsorption isotherms were analyzed using the density functional theory (DFT) method. Typically used to assess narrow pores in activated carbon [29], this method is a wellestablished way of assessing pore distributions below $1 \mathrm{~nm}$ because it overcomes the diffusion limitations for $\mathrm{N}_{2}$ which prevent it from entering the narrowest pores at $77 \mathrm{~K}[30]$. As such, it was deployed here 
to analyze the pore narrowing effects for the monoliths compared to their pristine powders, since these were found to occur at low diametric ranges and were not observable by $\mathrm{N}_{2}$ physisorption alone. To assess the binderless samples' macroporosities after calcination, mercury intrusion porosimetry (MIP) was performed using a low pressure sweep on a Quantichrome Poremaster. Therein, the pressure was swept from 0 to 30 psi under fixed rate, dwell time of zero, and motor speed of twelve. Here, it should be noted that only the low pressure sweep was performed because the monoliths' mechanical strengths were not very high, meaning that performing the high pressure sweep would decompose their structural integrity and lead to inaccurate nanopore assessment by MIP.
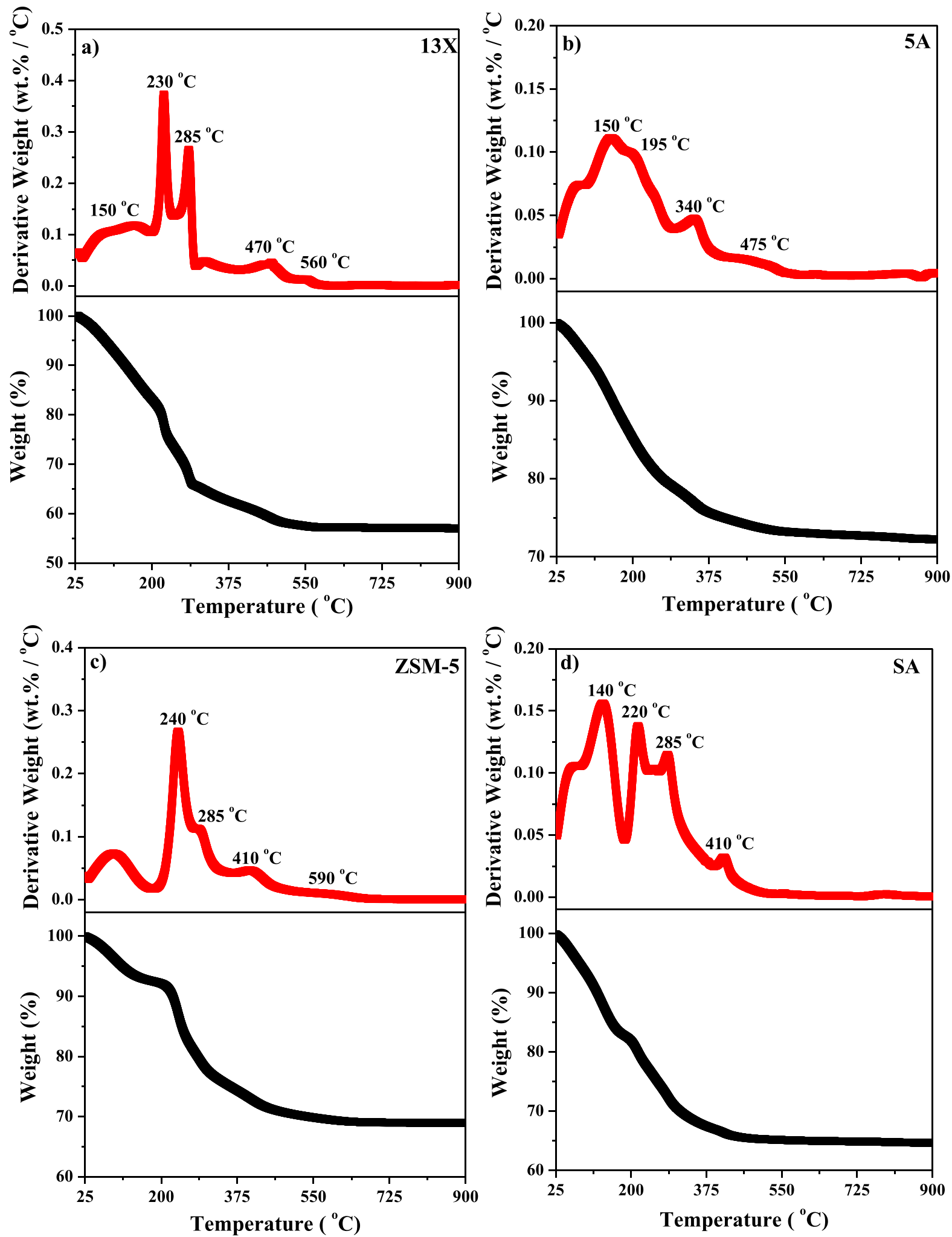

Fig. 2. Weight and derivative weight loss profiles from TGA for biopolymer-containing (a) $13 \mathrm{X}$, (b) $5 \mathrm{~A}$, (c) ZSM-5, and (d) $\mathrm{SA}$ monoliths from 25 to $900{ }^{\circ} \mathrm{C}$. 


\subsection{Adsorption measurements}

The $\mathrm{CH}_{4}, \mathrm{~N}_{2}$, and $\mathrm{CO}_{2}$ adsorption isotherms on both zeolite powders and calcined monoliths were measured on 3 Flex at $25^{\circ} \mathrm{C}$ from 0 to 1 bar. Prior to measurement, the samples were degassed using the conditions used from $\mathrm{N}_{2}$ physisorption. The corresponding $\mathrm{CO}_{2} / \mathrm{CH}_{4}$ and $\mathrm{CO}_{2} / \mathrm{N}_{2}$ selectivities from these isotherms were calculated by the IAST method [28]. The calcinated zeolite $13 \mathrm{X}$ and 5A monolith samples also underwent dynamic $\mathrm{CO}_{2}$ adsorption to compare their adsorption performances against commercial zeolite bead and powder analogues. Therein, the fractional adsorption uptake experiments were performed on the Q-500 TGA. Prior to analysis, the samples degassed at $400{ }^{\circ} \mathrm{C}$ for $1 \mathrm{~h}$ under $60 \mathrm{~mL} / \mathrm{min}$ of $\mathrm{N}_{2}$. The samples were then cooled to $25^{\circ} \mathrm{C}$ and the dynamic performances were assessed under $40 \mathrm{~mL} / \mathrm{min}$ of $10 \% \mathrm{CO}_{2} /$ $\mathrm{N}_{2}$ for $60 \mathrm{~min}$. The heating and cooling rates for each step were $10^{\circ} \mathrm{C} /$ min. The fractional uptakes were then calculated using a technique described in our previous work [31] and were modeled by varying the diffusivity to maximize the $\mathrm{R}^{2}$ values, as detailed previously [32,33]. For reference, the equations used for modeling are shown in Equations S1S3, Supporting Information.

\section{Results and discussion}

\subsection{Characterization results}

The TGA thermal decomposition profiles of the monoliths are shown in Fig. 2, whereas the bentonite/13X monoliths profiles are displayed in Fig. S1, Supporting Information. First, it should be noted here that the bentonite/13X monoliths all displayed a new peak at $500{ }^{\circ} \mathrm{C}$, which literature indicated could be attributed to dihydroxylation and dehydration of the minerals in bentonite clay $[34,35]$. Also worth noting, across all samples weight loss occurred below $100{ }^{\circ} \mathrm{C}$, however, this could be attributed to desorption of water and $\mathrm{CO}_{2}$. In other words, these peaks were not found to be indicative of the biopolymers' thermal decompositions. On the other hand, the peaks between 150 and $450{ }^{\circ} \mathrm{C}$ were representative of the known temperatures for pectin and gelatin thermal decomposition. To be specific, the gelatin containing samples i.e., the 13X (Fig. 1a), bentonite/13X (Fig. S1), and 5A (Fig. 1b) monoliths - all displayed a peak at $\sim 150{ }^{\circ} \mathrm{C}$, which coincides with combustion of gelatin biopolymers [36]. Notably, the SA monolith (Fig. 1d) also showed a peak at this range, however, because that zeolite was not commercially synthesized, and because the peak was much sharper compared to that for $13 \mathrm{X}$ and $5 \mathrm{~A}$, it can likely be contributed to some leftover contaminants from synthesis. Having said this, the SA monolith's peaks at 230 and $285{ }^{\circ} \mathrm{C}$ were concluded as pectin decomposition, since they were also present in the 13X, 5A, and ZSM-5 (Fig. 1c) monoliths, and corresponded to the known decomposition temperatures for pectin from literature [37]. Also worth noting here, all monoliths showed small peaks above $410{ }^{\circ} \mathrm{C}$, which can likely be attributed to combustion of leftover carbon from removing the biopolymer templates. Importantly, these peaks all occurred well below the calcination temperature of $550{ }^{\circ} \mathrm{C}$, meaning that the conditions selected were sufficient to fully extract the biopolymers. Granted, it is worth noting that the $13 \mathrm{X}$ and ZSM- 5 monoliths did show some weight loss between 560 and $590{ }^{\circ} \mathrm{C}$, however, this only led to a $1-2 \%$ reduction in sample weight and, therefore, was unlikely to produce any real effects on sorption properties. As such, the calcination temperature of $550{ }^{\circ} \mathrm{C}$ was concluded to be sufficient for extraction of the biopolymer additives.

The printed zeolite $13 \mathrm{X}$ monolith is shown in Fig. 3a-b, while the mechanical strengths as a function of bentonite loading are shown in Fig. 3c. There was no visual change between the uncalcined and calcined monoliths, meaning that sintering the zeolites and removing the biopolymers did not lead to structural shrinkage and the printed scaffold geometries could be easily replicated. Here, it should also be noted that the bentonite-containing zeolite $13 \mathrm{X}$ and binderless $5 \mathrm{~A}$ monoliths were visually indistinguishable from the zeolite $13 \mathrm{X}$ monolith. The SA and ZSM-5 monoliths were also indistinguishable, albeit with a diameter of $2 \mathrm{~cm}$ and channel thickness of $1.4 \mathrm{~mm}$ because of the thicker tips used for printing, instead of the $1.5 \mathrm{~cm}$ diameter piece with $0.5 \mathrm{~mm}$ channel thickness depicted in Fig. 3a-b. For these reasons, only the 13X monolith is shown here. As evident, this technique was able to produce monoliths which were self-standing and free of cracks, indicating that using sacrificial biopolymers is a facile means of printing binderless zeolite structures. Granted, the purely binderless monoliths were brittle (Fig. 3c), which was not surprising because mechanical strength is known to be caused by bridging between the active support and inert clay. Nevertheless, adding a mere $1 \mathrm{wt} \%$ of silica clay (i.e. bentonite) doubled the mechanical strength from the purely binderless monolith, whereas adding $2.5 \mathrm{wt} \%$ gave rise to a near six-fold enhancement in compressive strength. As such, the issue of low strength in binderless monoliths can clearly be addressed by adding small amounts of binding agent, where $2.5 \mathrm{wt} \%$ of bentonite can be considered an effective starting point for mechanical optimization. Notably, this binder concentration is still less than commercial binderless zeolite monoliths such as those produced by Ingevity corporation which include up to 10 $\mathrm{wt} \%$ binding agent - meaning that, for all intents and purposes,
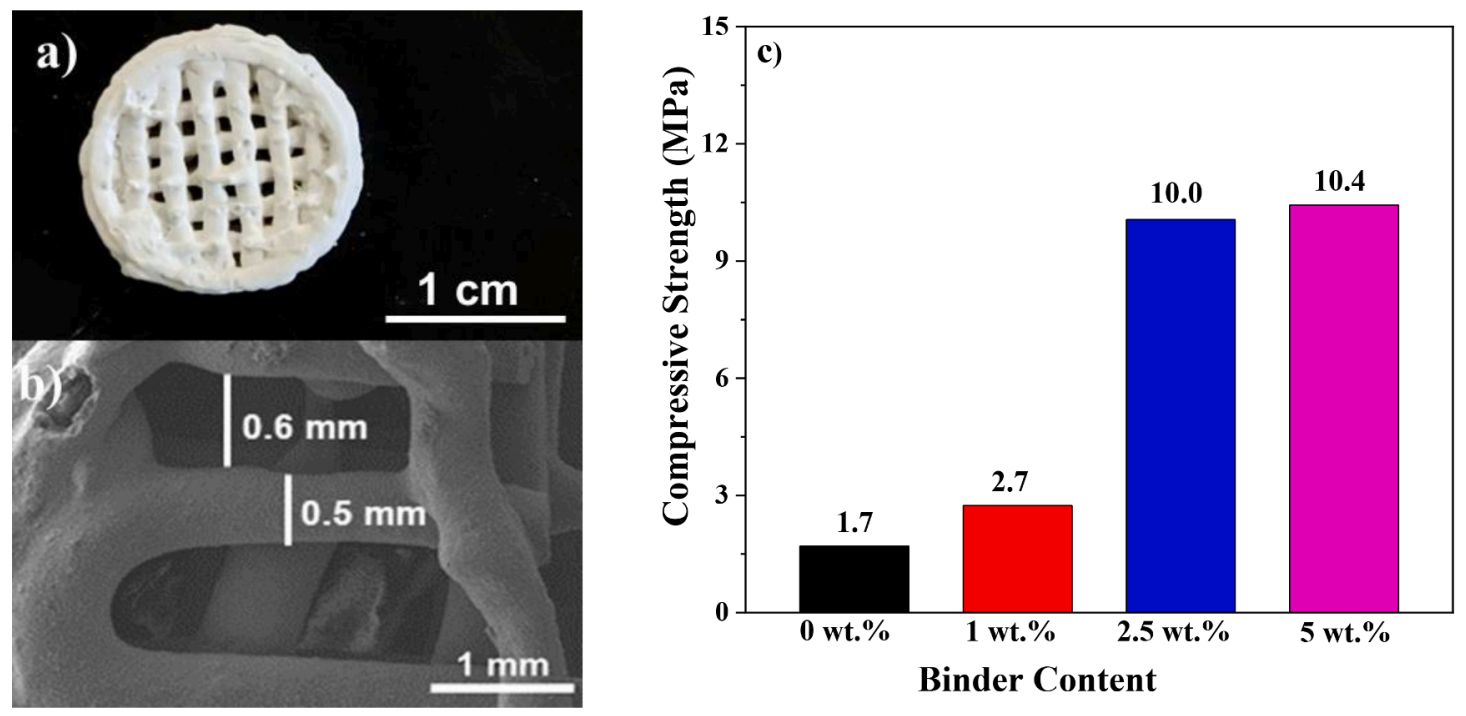

Fig. 3. Visual and SEM images of (a-b) zeolite 13X as well as (c) mechanical strengths of zeolite 13X monoliths with various bentonite loadings. 
monoliths with $1-5$ wt $\%$ of binder can be considered "binderless" materials, since they contain higher support loadings to commercial analogues that are included under the same classification [38]. Overall, the results displayed in Fig. 3 indicate a promising proof-of-concept for the manufacturing of binderless zeolite monoliths by 3D printing pectin and gelatin sacrificial biopolymers and demonstrate a versatile means of 3D printing binderless zeolites for the first time.

The SEM images of the intraparticle bonds within the calcined zeolite monoliths are shown in Fig. 4a-d, while the powder, uncalcined, and calcined XRD spectra are shown in Fig. 4e. As circled in yellow, all four zeolites exhibited intraparticle bridging, which was the source of mechanical strength for the purely binderless monoliths and prevented collapse of the printed structures. Between the four zeolites examined here, the intraparticle bonds were most apparent in the zeolite $13 \mathrm{X}$ (Fig. 4a) and SA (Fig. 4d) monoliths, where soldered bridges can clearly be observed. Notably, such sintering is known to occur when zeolites are calcined in the presence of binding agents, such as bentonite or halloysite nanotubes and, therefore, was somewhat anticipated from literature $[1,16,19]$. This being stated, to the best of our knowledge, this is the first time these bridges have ever been observed between individual zeolite particles, especially between particles in a printed ceramic, meaning that the SEM micrographs represent a novel piece of information pertaining to the physiomechanical properties of structured zeolites. Namely, the SEM images demonstrate that interparticle bonds not only form between zeolite particles and inert binding agents, but also can form between individual zeolite conglomerates themselves. As apparent from the XRD patterns (Fig. 4e), however, this bridging did not seem to affect the zeolites' crystal structures, since the calcined monoliths all exhibited diffractive indices which were consistent with their parent powders. Granted, it is worth noting here that the uncalcined samples showed losses in peak intensity and broadened diffractive indices, which could be attributed to obstruction of the crystal planes by the biopolymers, however, the index reformation after calcination indicated that the zeolites' crystallinities were intact. Therefore, on the basis of the results in Fig. 4 it was concluded that i) the source of mechanical strength in binderless zeolites stims from interparticle bridging and ii) 3D printing zeolite monoliths by using sacrificial gelatin and pectin biopolymers does not produce any significant change in the bulk zeolite structure.

The $\mathrm{N}_{2}$ physisorption isotherms and PSD profiles are shown in Fig. 5 , while the corresponding textural properties are summarized in Table 2.
Here, it is worth noting that, in the bentonite/13X samples, there was a small increase in surface area compared to the pure binderless monolith, however, this likely could be attributed to reduced bonding formed between the individual zeolite particles, on account of their bonding with the bentonite, which preserved some of the active sites. While these effects are interesting, they were found to not play significant roles in the monoliths' adsorption capacities and, therefore, are not overly important. What is important, however, is that across all commercial zeolites (i.e., 13X, 5A, and ZSM-5), Type I physisorption isotherms with Type H4 hysteresis was observed, which coincided with the IUPAC reports for microporous materials [39]. These isotherm and hysteresis shapes were also observed in the calcined SA samples (Fig. 5e), however, the powder exhibited a much lower $\mathrm{N}_{2}$ uptake than the monolith, which was not to be expected. On the one hand, this may have been caused by an incomplete ion exchange between the zeolitic $\mathrm{Na}$ and $\mathrm{H}$-forms. Otherwise, previous studies on this material indicated that the zeolite's pores are too narrow for $\mathrm{N}_{2}$ permeation at $77 \mathrm{~K}[26,27]$, meaning that definitive conclusions pertaining to differences in the monolith's and powder's textural properties could not be drawn $\mathrm{N}_{2}$ physisorption alone. The slight enhancement in surface area and pore volume implied that its active sites were more accessible to the condensing gas, thus suggesting that there was some degree of difference between the two materials' pore structures, possibly stemming from the interparticle bridging observed in in Fig. 4. These effects were further supported by the 13X (Fig. 5a), bentonite/13X (Fig. 5b), ZSM-5 (Fig. 5d), PSD profiles, where small shifts from the meso- to microporous regimes were observed after calcination, suggesting that a narrowing effect was present. However, because this shift was not present for the 5A samples (Fig. 5c), the differences in pore structures between the as-received zeolite powders and binderless monoliths required further analysis to precisely elucidate these effects.

To investigate the differences in textural properties between the powdered and binderless zeolites posed by Fig. $5, \mathrm{CO}_{2}$ adsorption isotherms were collected at $0{ }^{\circ} \mathrm{C}$ from 0 to 1 bar, since $\mathrm{CO}_{2}{ }^{\prime}$ s diameter under these conditions can better fill the small sorbent pores compared to $\mathrm{N}_{2}$ at 77 K $[29,30]$. The DFT pore distributions collected from these experiments are displayed in Fig. 6, while the corresponding peak heights and areas are summarized in Table S1, Supporting Information. As evident, most of the zeolites exhibited slight diametric pore narrowing after formulation into binderless monoliths. As observed from Fig. 4, these effects could have been caused by slight malformation of the pore
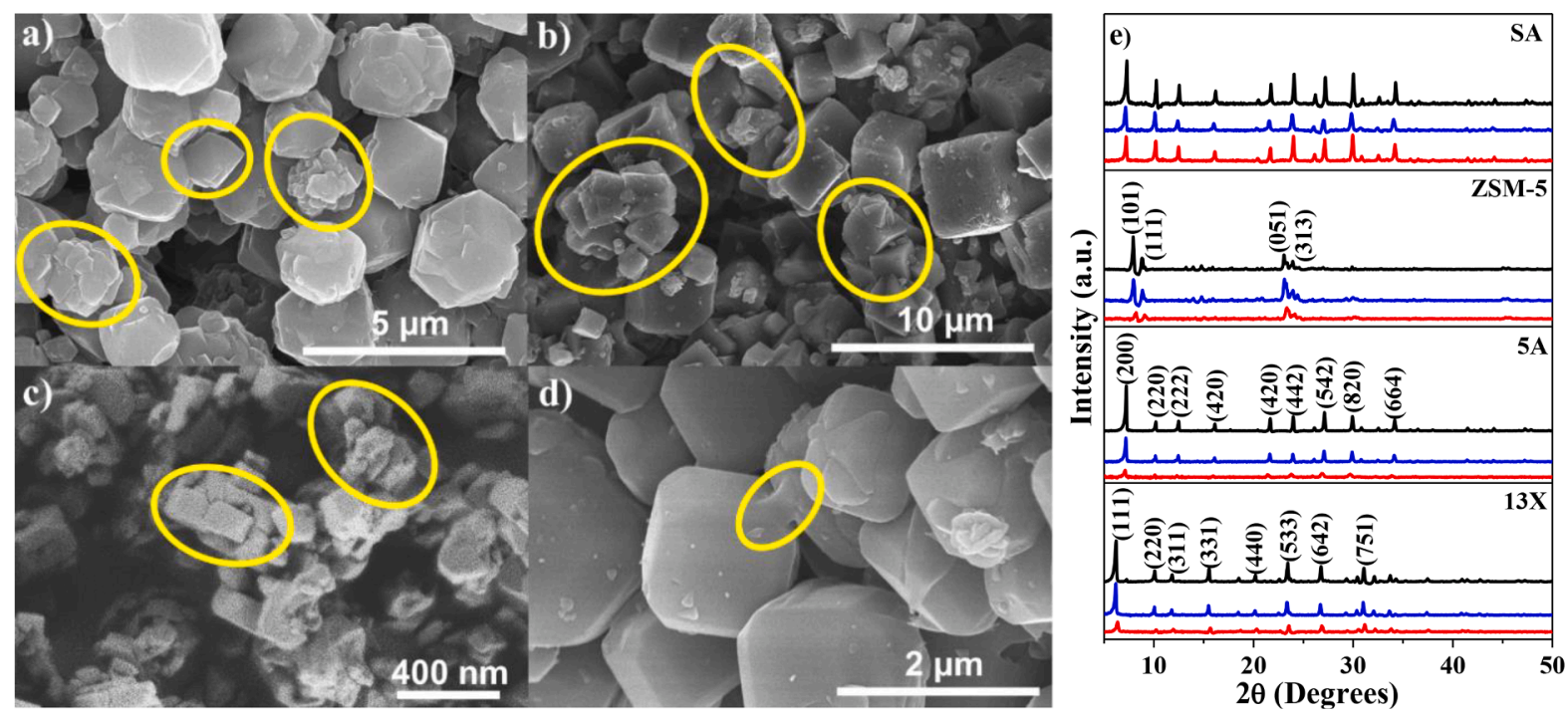

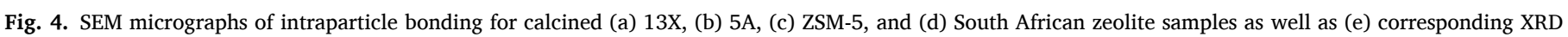

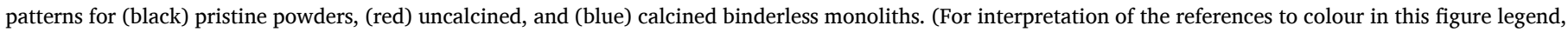
the reader is referred to the web version of this article.) 

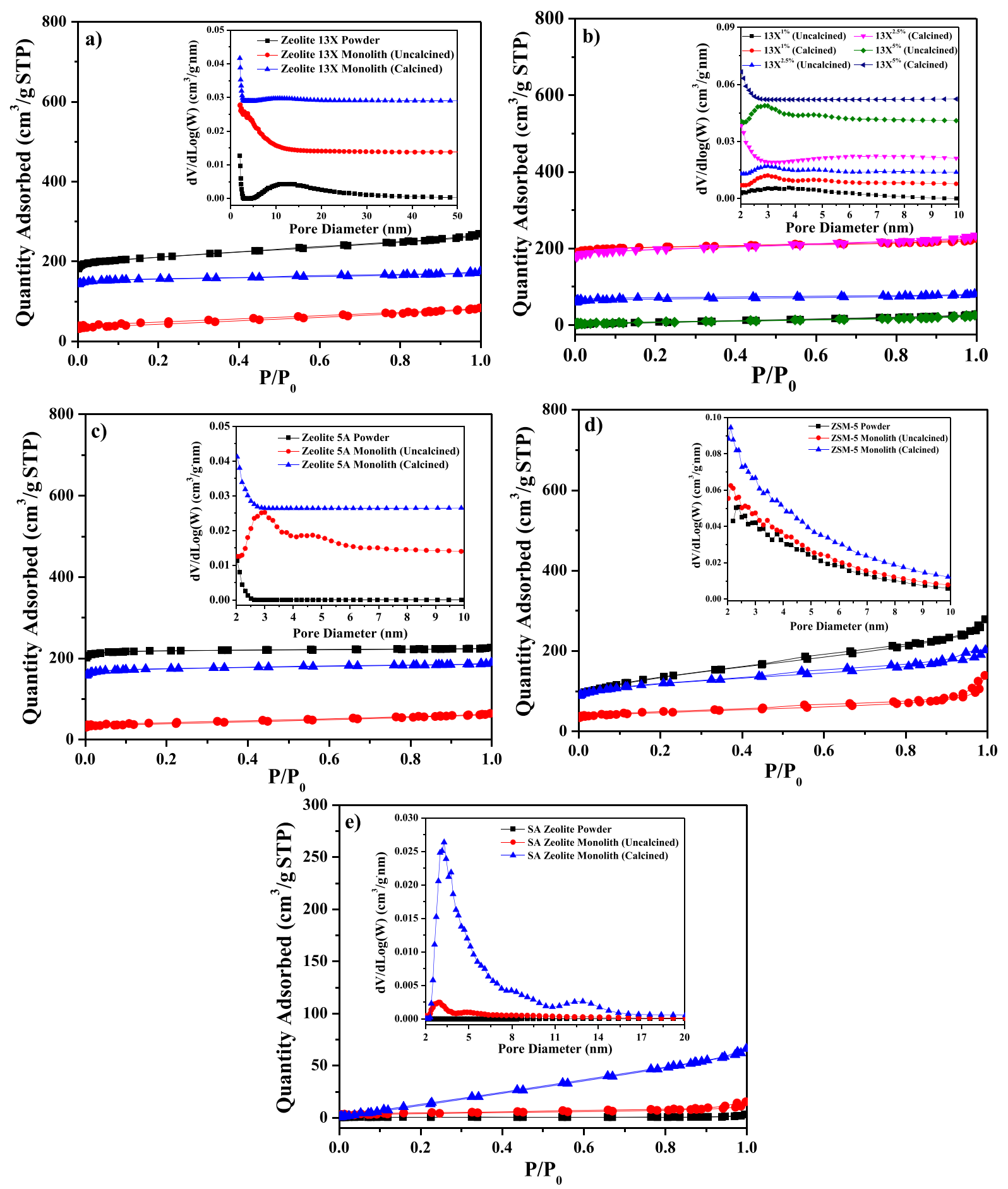

Fig. 5. $\mathrm{N}_{2}$ physisorption isotherms and NLDFT pore distributions (nested) for (a) 13X, (b) bentonite/13X (c) 5A, (d) ZSM-5, and (e) South African zeolite powders, uncalcined, and calcined monoliths at $77 \mathrm{~K}$.

structure stimming from the interparticle bridging at high temperature [40]. Although this phenomenon did not yield any discernable changes in the bulk crystalline phases, as was evidenced by the XRD patterns, it did give rise to pronounced changes in micropore sizing. Evidently, these effects changed from one zeolite to another, which was not surprising given that the physiochemical properties across crystallite families are not constant and, therefore, should yield differences in sintering behavior. Granted, all samples did exhibit a peak at $0.367 \mathrm{~nm}$, however, because this peak was not fully formed, it should be considered a lower bound of the DFT technique with $\mathrm{CO}_{2}$ at $0{ }^{\circ} \mathrm{C}$ and not representative of the micropore distributions. Nevertheless, some useful information was gathered from the narrow pore range in the zeolite 5A samples (Fig. 6b). Specifically, although the $5 \mathrm{~A}$ samples displayed no discernable pore diameter shift after 3D printing, the monolith's peaks at 0.367 and $0.437 \mathrm{~nm}$ increased in height by $10 \%$ and $5 \%$, respectively, compared to the powder. This strongly suggested that the structured material contained additional micropore space, which could have been caused by a diametric shift from 1 to $2 \mathrm{~nm}$ in the powder towards $0.4-1 \mathrm{~nm}$ in the monolith. While there is not a technique to definitively prove this theory, it was also strongly supported by the other zeolites' DFT profiles 
Table 2

Textural properties for the zeolite powders, uncalcined, and calcined monoliths.

\begin{tabular}{|c|c|c|c|c|}
\hline Sample & $\begin{array}{l}\mathrm{S}_{\mathrm{BET}} \\
\left(\mathrm{m}^{2} / \mathrm{g}\right)\end{array}$ & $\begin{array}{l}\mathrm{V}_{\mathrm{p}-\text { micro }} \\
\left(\mathrm{cm}^{3} / \mathrm{g}\right)\end{array}$ & $\begin{array}{l}\mathrm{V}_{\mathrm{p}-\mathrm{meso}} \\
\left(\mathrm{cm}^{3} / \mathrm{g}\right)\end{array}$ & $\begin{array}{l}\text { NLDFT Pore } \\
\text { Size (nm) }\end{array}$ \\
\hline 13X Powder & 660 & 0.30 & 0.08 & 2,10 \\
\hline $\begin{array}{l}\text { 13X Monolith } \\
\text { (Uncalcined) }\end{array}$ & 150 & 0.05 & 0.06 & $2-10$ \\
\hline $\begin{array}{l}\text { 13X Monolith } \\
\text { (Calcined) }\end{array}$ & 550 & 0.30 & 0.02 & 2,10 \\
\hline $13 \mathrm{X}^{1 \%}$ (Uncalcined) & 30 & 0.00 & 0.03 & $2-10$ \\
\hline $13 \mathrm{X}^{1 \%}$ (Calcined) & 640 & 0.29 & 0.03 & 2,5 \\
\hline $13 \mathrm{X}^{2.5 \%}$ (Uncalcined) & 210 & 0.09 & 0.02 & 3,6 \\
\hline $13 \mathrm{X}^{2.5 \%}$ (Calcined) & 620 & 0.29 & 0.04 & $2,3-15$ \\
\hline $13 \mathrm{X}^{5 \%}$ (Uncalcined) & 30 & 0.01 & 0.02 & 2.3 \\
\hline $13 \mathrm{X}^{5 \%}$ (Calcined) & 590 & 0.29 & 0.02 & $2,10-20$ \\
\hline 5A Powder & 660 & 0.32 & 0.00 & 2 \\
\hline $\begin{array}{l}\text { 5A Monolith } \\
\text { (Uncalcined) }\end{array}$ & 130 & 0.05 & 0.03 & $2,4,6$ \\
\hline 5A Monolith (Calcined) & 540 & 0.26 & 0.01 & 2,15 \\
\hline ZSM-5 Powder & 470 & 0.15 & 0.15 & 2 \\
\hline $\begin{array}{l}\text { ZSM-5 Monolith } \\
\text { (uncalcined) }\end{array}$ & 160 & 0.06 & 0.09 & $2,6,8$ \\
\hline $\begin{array}{l}\text { ZSM-5 Monolith } \\
\text { (calcined) }\end{array}$ & 390 & 0.15 & 0.12 & 2 \\
\hline SA Zeolite Powder & 2 & 0.00 & 0.002 & $10-35$ \\
\hline $\begin{array}{l}\text { SA Zeolite Monolith } \\
\text { (uncalcined) }\end{array}$ & 14 & 0.004 & 0.015 & $3,7,9,18-38$ \\
\hline $\begin{array}{l}\text { SA Zeolite Monolith } \\
\text { (calcined) }\end{array}$ & 96 & 0.00 & 0.090 & 4,14 \\
\hline
\end{tabular}

where clear narrowing was observed.

For example, the $13 \mathrm{X}$ powder exhibited pore diameters at $0.474-0.507$ and $0.648-0.681 \mathrm{~nm}$ (Fig. 6a), however, the $0.474 \mathrm{~nm}$ peak shifted to $0.472,0.473,0.453$, and $0.455 \mathrm{~nm}$ in the binderless, $13 \mathrm{X}^{1 \%}$, $13 \mathrm{X}^{2.5 \%}$, and $13 \mathrm{X}^{5 \%}$ samples, respectively, while the $0.681 \mathrm{~nm}$ peak shifted towards $0.559,0.561,0.576$, and $0.559 \mathrm{~nm}$, respectively. Notably, the shift at $0.474 \mathrm{~nm}$ was not significant in the binderless and $13 \mathrm{X}^{1 \%}$ samples, however, the higher bentonite loadings gave rise to increased narrowing at that range, likely caused by binder intrusion into the pore window $[41,42]$. Nevertheless, these effects were marginal and not overly significant, as evidenced by the $13 \mathrm{X}^{2.5-5 \%}$ samples' higher surface areas compared to the binderless monolith (Table 2). On the other hand, the monoliths' diametric shifts at $0.648 \mathrm{~nm}$ were much more substantial, as that pore diameter reduced in size by $\sim 20 \%$ regardless of the binder concentration and, therefore, could likely be attributed to intraparticle zeolite bridging. A similar effect was also observed in the SA zeolite samples (Fig. 6d), where the powder's peak at $0.471 \mathrm{~nm}$ shifted towards $0.435 \mathrm{~nm}$ in the monolith, while the peak at $0.611 \mathrm{~nm}$ became nonexistent. The latter peak's disappearance was likely caused by a shift to the $0.435 \mathrm{~nm}$ range, as further evidenced by the $70 \%$ increase in peak area for the monolith relative to the powder between 0.4 and $0.6 \mathrm{~nm}$. It is also worth noting that the monolith showed a decrease in pore volume below $0.367 \mathrm{~nm}$ compared to the powder, indicating that some of the zeolite's micropores had broadened. This agreed with the textural properties from $\mathrm{N}_{2}$ physisorption, where the monolith displayed a higher surface area, thereby suggesting that the micropores had become more accessible to $\mathrm{N}_{2}$ condensation. As evident, the $\mathrm{CO}_{2}$ isotherms at $0{ }^{\circ} \mathrm{C}$ corroborated this conclusion, since the monolith's pore distribution indicated that the narrowest micropores had increased in diameter to some degree relative to the parent SA powder. In the ZSM-5 samples (Fig. 6c), the powder displayed several micropore ranges between 0.4 and $0.9 \mathrm{~nm}$, all of which shifted towards $0.367,0.439$, and $0.576 \mathrm{~nm}$ in the monolith. Compared to the other zeolites, the pore narrowing effects were much more prevalent for ZSM-5. As previously noted, these pronounced changes could probably be attributed to differences in the zeolites' physiochemical properties, since these parameters are known to affect bridging behavior. Nonetheless, such characteristics should be the target of subsequent studies, as the work here is simply focused on demonstrating a versatile method of binderless zeolite printing and characterizing its effects on the monoliths' physiochemical properties. In this regard, the dataset in Fig. 6 can be used to generate an important conclusion. Namely that, although zeolite/ biopolymer printing does not impact crystallinity, it does produce changes in micropore sizing which can lead to pronounced differences in adsorption behavior compared to the parent powders.

As a supplement to the other pore characterizations, low-pressure MIP was performed on the various binderless zeolite monoliths to assess the hierarchal macropore distribution produced by biopolymer extraction. The MIP profiles are shown in Fig. 7. As can be seen, the highest macropore volume was observed in the binderless zeolite 13X monolith. This was not surprising, since the $13 \mathrm{X}$ monolith ink contained $\sim 50 \mathrm{wt} \%$ of organic binder, whereas the other samples' binder contents ranged from 7.9 to $25 \mathrm{wt} \%$. In other words, this result was not surprising, since increasing the printing ink's organic concentration is known to increase macrovoid space produced during template removal [16]. As apparent, the $13 \mathrm{X}$ monolith's higher binder concentration also led to a macropore diameter shift towards larger voids, since most of the pore space was allocated above $20 \mu \mathrm{m}$. Granted, the zeolite 5A (Fig. 7b), ZSM-5 (Fig. 7c) and South African (Fig. 7d) monoliths also displayed some macropore volumes above this threshold, however, they were not as pronounced as the $13 \mathrm{X}$ sample, meaning that their hierarchal pore structure was more evenly distributed from 1 to $100 \mu \mathrm{m}$. Having said this, it was clearly concluded that - regardless of the polymeric binder concentration - this new printing method generates a hierarchal macropore structure with considerable pore space. Stimming from this, it was anticipated that the binderless monoliths would display enhanced mass transfer properties compared to conventionally printed bentonite/ zeolite monoliths produced by direct ink writing, as elevating the macropore volume has been shown to reduce barriers to molecular diffusion and lead to sharper mass transfer kinetics $[15,16]$. Indeed, this was observed in the fractional uptakes, as will be discussed in subsequent sections. From these analyses, the pore volumes of the samples were estimated to be $3.1,0.3,0.15$, and $0.1 \mathrm{~cm}^{3} / \mathrm{g}$ for $13 \mathrm{X}, 5 \mathrm{~A}$, ZSM-5 and SA zeolite monoliths.

\subsection{Adsorption measurement results}

The $\mathrm{CO}_{2}, \mathrm{~N}_{2}$, and $\mathrm{CH}_{4}$ adsorption isotherms and IAST $\mathrm{CO}_{2}$ selectivities are displayed in Fig. 8. First, it should be noted that all monoliths exhibited comparable $\mathrm{CO}_{2} / \mathrm{CH}_{4}$ and $\mathrm{CO}_{2} / \mathrm{N}_{2}$ selectivities to the parent powders, where varying increases and decreases were observed because of differences between the measured $\mathrm{CO}_{2}, \mathrm{~N}_{2}$, and $\mathrm{CH}_{4}$ adsorption capacities of the four samples. To be more specific, all binderless monoliths showed increased $\mathrm{CO}_{2}$ adsorption uptakes compared to the pristine powders, where the $\mathrm{N}_{2}$ and $\mathrm{CH}_{4}$ adsorption capacities also increased by varying degrees in the 13X (Fig. 8a-b), 5A (Fig. 8c-e), and ZSM-5 (Fig. 8fh) monoliths. Notably, these effects were consistent with the diametric narrowing observed in Fig. 6, as slight shrinkage of the pore window can yield enhanced electrostatic interactions between the captured guests and adsorbent walls, thereby increasing the adsorption capacity even if the surface area and pore volume are lower $[43,44]$. Granted, the SA zeolite monolith (Fig. 8i-k) exhibited a reduced $\mathrm{CH}_{4}$ adsorption capacity and nearly identical $\mathrm{N}_{2}$ adsorption capacity compared to its parent powder, however, this sample also showed a degree of pore broadening which likely can be considered the source of these effects. Otherwise, it is possible that unforeseen factors affected the SA monoliths' storage capacity, since the zeolite was not commercially synthesized. As such, the SA zeolite monolith's adsorption isotherms are less statistically significant relative to $13 \mathrm{X}, 5 \mathrm{~A}$, and ZSM-5. In those samples, however, the benefits of pore narrowing can be clearly observed, as all three monoliths exhibited enhanced adsorption capacities relative to their parent powders. To the best of our knowledge, this is the first time that such a phenomenon has ever been observed for binderless zeolite monoliths, much less binderless monoliths produced by 3D printing, and represents a novel way of tuning structured zeolites' adsorptive 

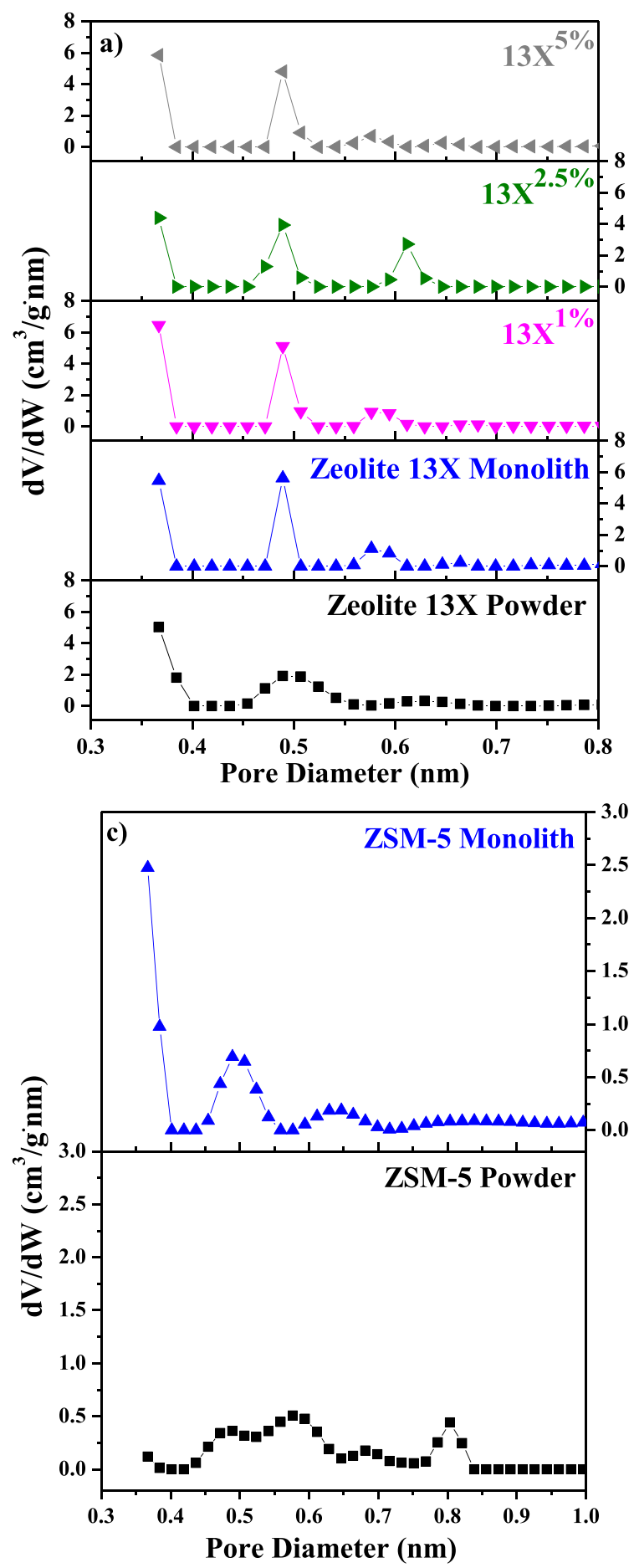
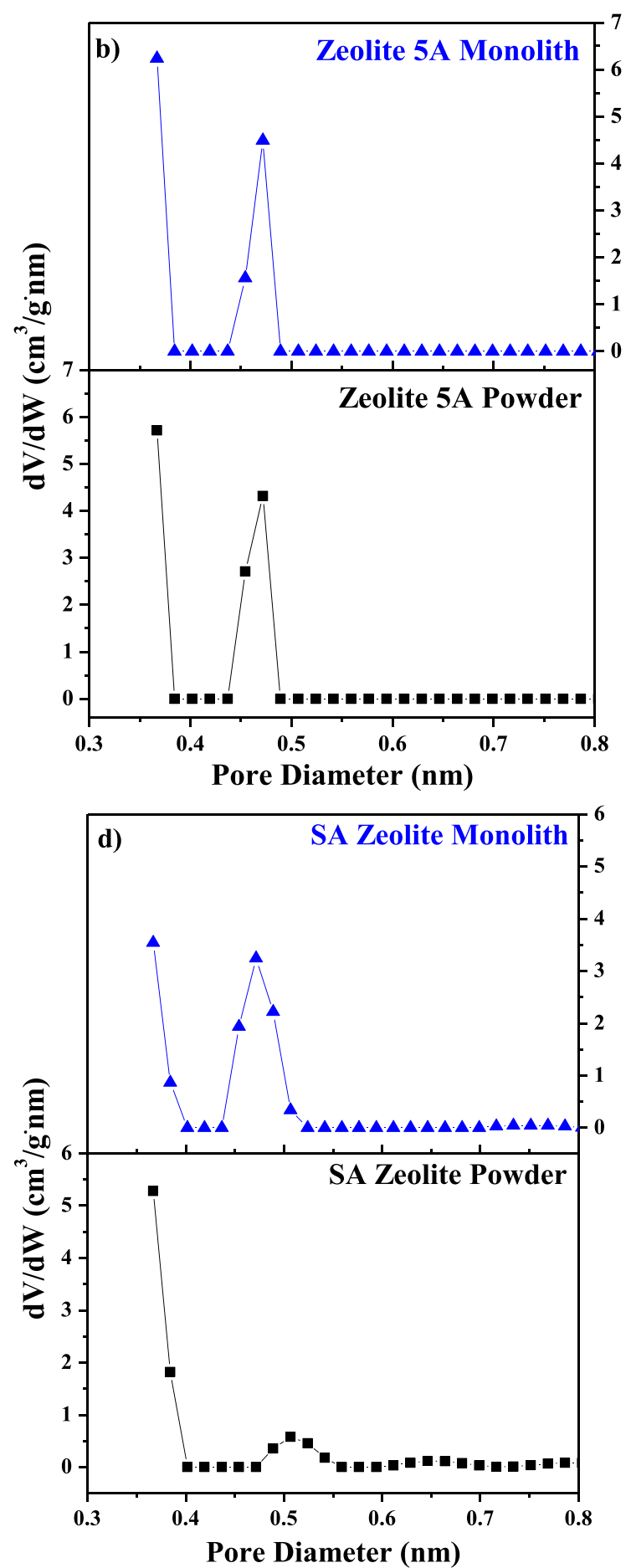

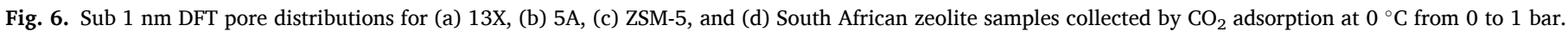

properties.

The fractional $10 \% \mathrm{CO}_{2} / \mathrm{N}_{2}$ uptakes at $25{ }^{\circ} \mathrm{C}$ for the various $13 \mathrm{X}$ and 5A zeolite materials are displayed in Fig. 9, while the calculated adsorption capacities and diffusivities are summarized in Table 3. Here, it should first be noted that all $\mathrm{R}^{2}$ values exceeded 0.98 , indicating that the selected model and diffusivity values accurately represented the fractional adsorption uptakes. It should also be noted here that, between the various monoliths tested, only the binderless $13 \mathrm{X}$ sample exhibited a higher $\mathrm{CO}_{2}$ adsorption capacity than its parent powder. Quite likely, this was caused by the monoliths' enhanced $\mathrm{N}_{2}$ adsorption capacity, which led to more pore filling while equilibrating the furnace at $25{ }^{\circ} \mathrm{C}$. This being stated, the differences between the powders and monoliths were not very high, meaning that the mass transfer properties can be considered better heuristics for assessing their performances as adsorbent materials.

In this regard, both the bentonite/13X (Fig. 9a-b) and 5A (Fig. 9c-d) monoliths displayed slightly broader fractional uptakes compared to the commercial beads. This was not surprising, as our earlier works have repeatedly proven that printed monolith mass transfer is dependent on molecular diffusion, which is always inhibited to some degree by pore blockage from the inert binder $[15,16]$. This being the case, these effects were not very substantial, as the low-binder containing monoliths 

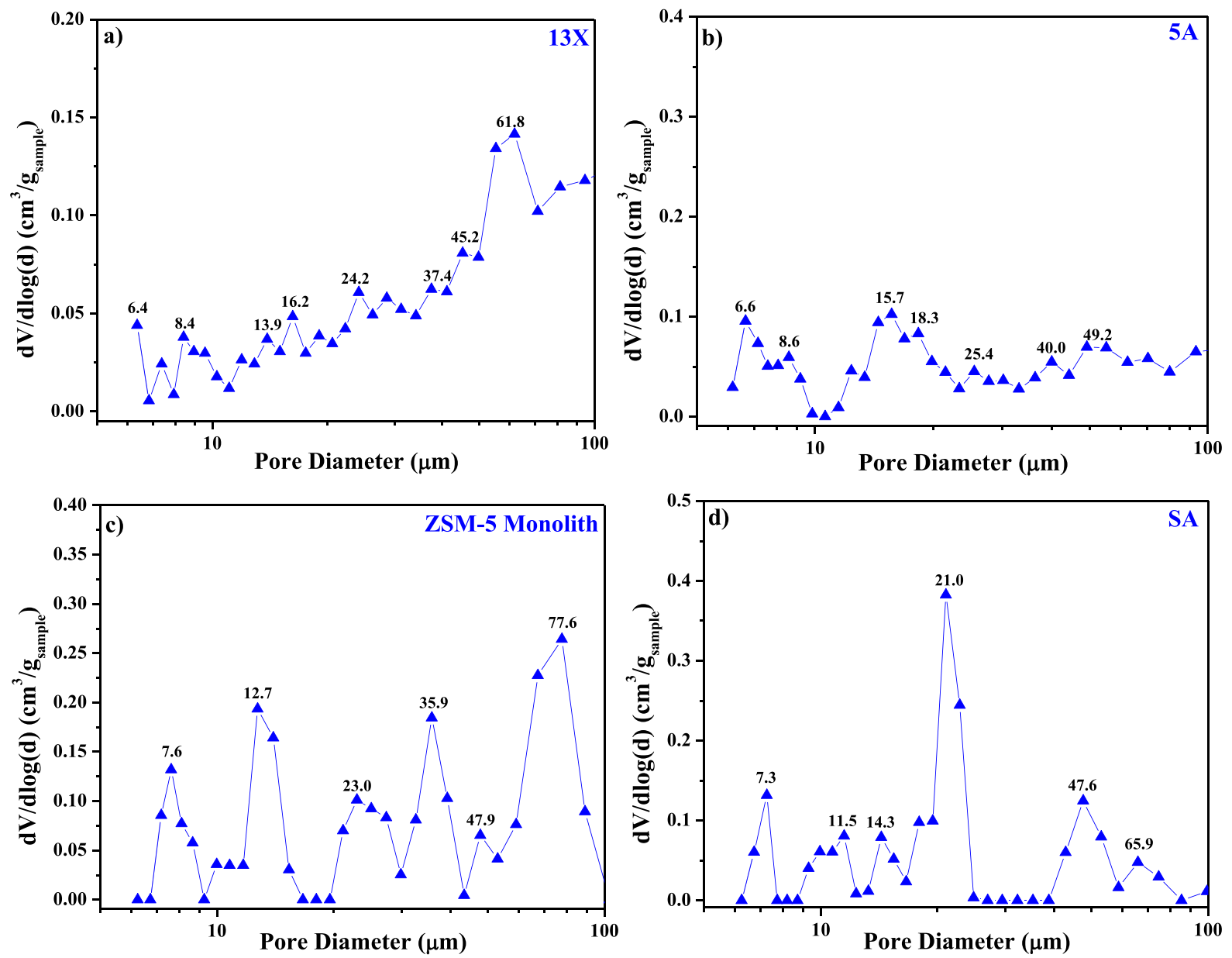

Fig. 7. Low pressure MIP profiles for (a) 13X, (b) 5A, (c) ZSM-5 and (d) SA monoliths produced by 3D printing sacrificial biopolymers.

exhibited nearly identical diffusivities to those of the purely binderless beads and monoliths and, also, displayed much faster kinetics compared to the $13 \mathrm{X} / \mathrm{R} 4$ monolith produced by our previous technique [1]. Also worth noting here, similar properties were observed in the binderless $5 \mathrm{~A}$ monolith, however, its transport was much slower relative to its powder and bead analogues compared to 13X. Granted, the 5A powder and beads both displayed faster diffusivities compared to the $13 \mathrm{X}$ powder and beads, so comparing the various monoliths' transport properties can be considered a better representation of the materials' kinetic behaviors. In this regard, the binderless 5A monolith's kinetics were also faster than its R4 counterpart and were even slightly faster than the binderless $13 \mathrm{X}$ sample. This was surprising considering that the $5 \mathrm{~A}$ monolith was significantly less macroporous than the $13 \mathrm{X}$ monolith, effectively indicating that biopolymer burnout produces mass transfer benefits even when the template concentration is low. Moreover, both the binderless and bentonite/13X monoliths displayed vastly enhanced kinetics compared to their R4 analogues, as well as comparable diffusivities to their commercial bead counterparts, which represented a fundamental improvement for 3D-printed monolith mass transport properties. Namely, biopolymer printing and calcination overcomes the limitation of molecular diffusion posed by conventional additive manufacturing and gives rise to scaffolds with comparable kinetic properties to commercial geometries. Granted, continuous adsorption/desorption experiments should be performed to further investigate these materials' process performance and better understand such properties, however, these experiments should be targeted in a separate study, since this work is solely focused on developing a means to 3D-print binderless zeolite monoliths for the first time.

\section{Conclusions}

In this study, we demonstrated a novel approach for formulating binderless zeolite monoliths across four different families by utilizing gelatin and pectin biopolymers in ink formulation. Unlike other approaches, this so-called "sacrificial biopolymer" style of 3D printing produced printable inks in under five minutes. Moreover, as was evidenced by the various pore analyses and adsorption isotherms, calcining zeolites alongside gelatin and pectin lead to narrowing of the pore windows and gave rise to enhanced adsorption capacities. As yet another benefit, the binderless monoliths exhibited comparable mass transfer properties to those of commercial benchmarks, which was demonstrated to be an improvement on conventional 3D printing, where the dynamic rate is critically dampened by molecular mass transfer. Therefore, the technique demonstrated in this study represents a novel and important breakthrough in additive manufacturing, since it is the first ever known means of formulating $100 \%$ pure zeolite scaffolds for virtually any family, allows for rapid printing, and yields enhanced physiochemical properties compared to the pristine powder. Granted, there are still improvements to be made in order to impart better mechanical strength and geometric control, however, such challenges are small compared to developing the printing method itself. As such, this work represents an important first step in the advancement of zeolite 3D printing technology.

\section{Declaration of Competing Interest}

The authors declare that they have no known competing financial 

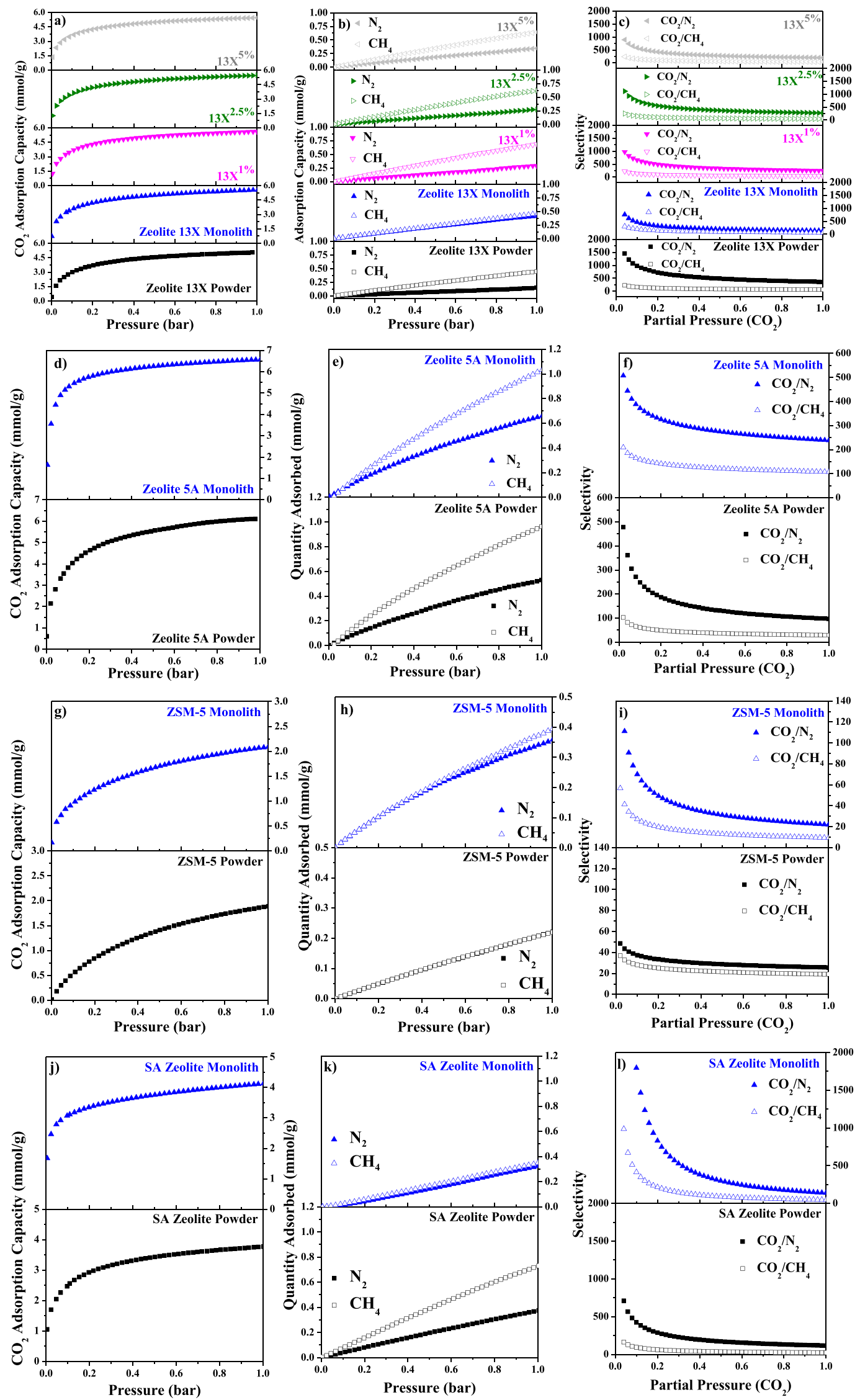

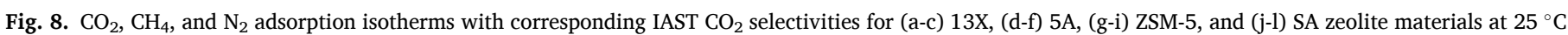
from 0 to 1 bar. 

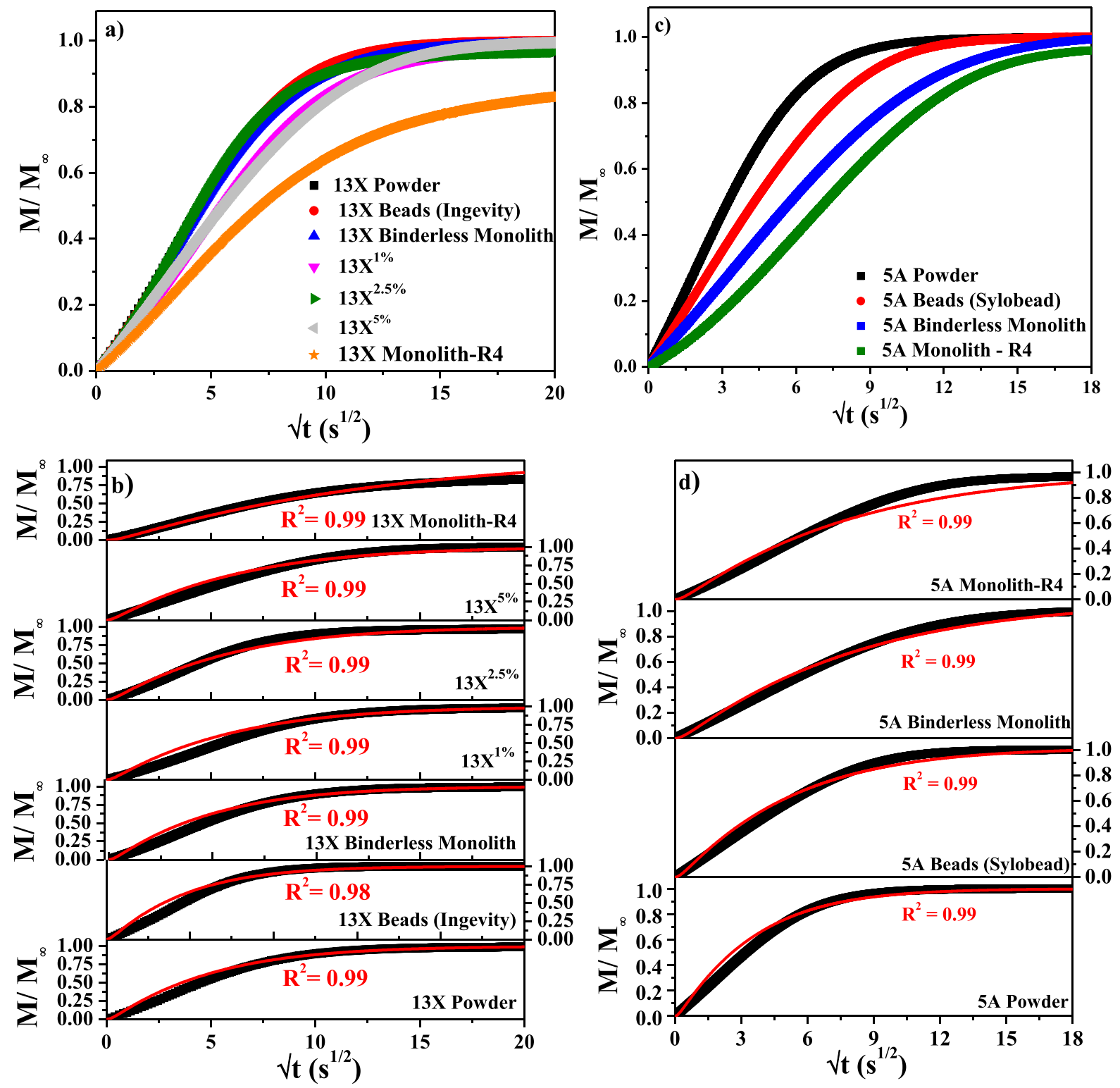

Fig. 9. Fractional $10 \% \mathrm{CO}_{2} / \mathrm{N}_{2}$ adsorption uptakes (symbols) and corresponding fitted profiles (lines) for (a-b) $13 \mathrm{X}$ and (c-d) $5 \mathrm{~A}$ zeolite materials at $25{ }^{\circ} \mathrm{C}$.

Table 3

$\mathrm{CO}_{2}$ Adsorption capacities and diffusivity values from normalized uptake experiments.

\begin{tabular}{lll}
\hline Sample & $\begin{array}{l}\mathrm{CO}_{2} \text { Adsorption Capacity } \\
(\mathrm{mmol} / \mathrm{g})\end{array}$ & $\begin{array}{l}\text { Diffusivity } \times 10^{9}\left(\mathrm{~cm}^{2} /\right. \\
\mathrm{s})\end{array}$ \\
\hline 13X Powder & 3.3 & 1.3 \\
13X Beads (Ingevity) & 3.3 & 1.4 \\
13X Binderless & 3.5 & 1.3 \\
$\quad$ Monolith & & \\
13X & & 1.1 \\
13X & & \\
13X\% & 3.5 & 1.4 \\
13X Monolith - R4 & 3.4 & 1.1 \\
5A Powder & 3.0 & 1.0 \\
5A Beads (Sylobead) & 3.0 & 3.5 \\
5A Binderless & 3.7 & 2.0 \\
$\quad$ Monolith & & 1.6 \\
5A Monolith - R4 & 3.5 & 1.5 \\
\hline
\end{tabular}

interests or personal relationships that could have appeared to influence the work reported in this paper.

\section{Acknowledgements}

The authors acknowledge University of Missouri-University of the Western Caper (UMUWC) Award for financially supporting this project. The authors also acknowledge Oak Ridge National Lab (ORNL) for providing access to SEM equipment. The involvement of Shane Lawson in this work was sponsored by the National Science Foundation internship program (NSF CBET-1802049).

Appendix A. Supplementary data

Supplementary data to this article can be found online at https://doi. org/10.1016/j.cej.2020.128011. 


\section{References}

[1] H. Thakkar, S. Eastman, A. Hajari, A.A. Rownaghi, J.C. Knox, F. Rezaei, 3D-printed zeolite monoliths for $\mathrm{CO} 2$ removal from enclosed environments, ACS Appl. Mater. Interfaces (2016) 27753-27761, https://doi.org/10.1021/acsami.6b09647.

[2] F. Magzoub, X. Li, J. Al-Darwish, F. Rezaei, A.A. Rownaghi, 3D-printed ZSM-5 monoliths with metal dopants for methanol conversion in the presence and absence of carbon dioxide, Appl. Catal. B 245 (2019) 486-495, https://doi.org/10.1016/j. apcatb.2019.01.008.

[3] K. Kupiec, J. Rakoczy, E. Lalik, Modeling of PSA separation process including friction pressure drop in adsorbent bed, Chem. Eng. Process. Process Intensif. 48 (7) (2009) 1199-1211, https://doi.org/10.1016/j.cep.2009.04.009.

[4] L. Riboldi, O. Bolland, Overview on pressure swing adsorption (PSA) as CO2 capture technology: state-of-the-art, limits and potentials, Energy Procedia 114 (2017) 2390-2400, https://doi.org/10.1016/j.egypro.2017.03.1385.

[5] Y. Wang, L.i. Zhao, A. Otto, M. Robinius, D. Stolten, A review of post-combustion CO2 capture technologies from coal-fired power plants, Energy Procedia 114 (2017) 650-665, https://doi.org/10.1016/j.egypro.2017.03.1209.

[6] X. Li, W. Li, F. Rezaei, A. Rownaghi, Catalytic cracking of n-hexane for producing light olefins on 3D-printed monoliths of MFI and FAU zeolites, Chem. Eng. J. 333 (2018) 545-553, https://doi.org/10.1016/j.cej.2017.10.001.

[7] A. Aranzabal, D. Iturbe, M. Romero-Sáez, M.P. González-Marcos, J.R. González Velasco, J.A. González-Marcos, Optimization of process parameters on the extrusion of honeycomb shaped monolith of H-ZSM-5 zeolite, Chem. Eng. J. 162 (1) (2010) 415-423, https://doi.org/10.1016/j.cej.2010.05.043.

[8] Y.Y. Li, S.P. Perera, B.D. Crittenden, J. Bridgwater, The effect of the binder on the manufacture of a 5A zeolite monolith, Powder Technol. 116 (1) (2001) 85-96, https://doi.org/10.1016/S0032-5910(00)00366-1.

[9] B. Mette, H. Kerskes, H. Drück, H. Müller-Steinhagen, Experimental and numerica investigations on the water vapor adsorption isotherms and kinetics of binderless zeolite 13X, Int. J. Heat Mass Transf. 71 (2014) 555-561, https://doi.org/10.1016 j.ijheatmasstransfer.2013.12.061.

[10] J.A.C. Silva, K. Schumann, A.E. Rodrigues, Sorption and kinetics of $\mathrm{CO} 2$ and $\mathrm{CH}_{4}$ in binderless beads of 13X zeolite, Microporous Mesoporous Mater. 158 (2012) 219-228, https://doi.org/10.1016/j.micromeso.2012.03.042.

[11] H. Thakkar, S. Eastman, Q. Al-Naddaf, A.A. Rownaghi, F. Rezaei, 3D-printed metal-organic framework monoliths for gas adsorption processes, ACS Appl. Mater. Interfaces 9 (41) (2017) 35908-35916, https://doi.org/10.1021/ acsami.7b11626.s001.

[12] H. Thakkar, Q. Al-Naddaf, N. Legion, M. Hovis, A. Krishnamurthy, A.A. Rownaghi, F. Rezaei, Adsorption of ethane and ethylene over 3D-printed ethane-selective monoliths, ACS Sustainable Chem. Eng. 6 (11) (2018) 15228-15237, https://doi. org/10.1021/acssuschemeng.8b03685.s001.

[13] H. Thakkar, S. Lawson, A.A. Rownaghi, F. Rezaei, Development of 3D-printed polymer-zeolite composite monoliths for gas separation, Chem. Eng. J. 348 (2018) 109-116, https://doi.org/10.1016/j.cej.2018.04.178.

[14] S. Lawson, Q. Al-Naddaf, A. Krishnamurthy, M.S. Amour, C. Griffin, A A. Rownaghi, J.C. Knox, F. Rezaei, UTSA-16 growth within 3D-printed co-kaolin monoliths with high selectivity for $\mathrm{CO} 2 / \mathrm{CH} 4, \mathrm{CO} 2 / \mathrm{N} 2$, and $\mathrm{CO} 2 / \mathrm{H} 2$ separation, ACS Appl. Mater. Interfaces 10 (2018) 19076-19086, https://doi.org/10.1021/ acsami.8b05192.

[15] S. Lawson, C. Griffin, K. Rapp, A.A. Rownaghi, F. Rezaei, Amine-functionalize MIL-101 monoliths for CO2 removal from enclosed environments, Energy Fuels 33 (2019) 2399-2407, https://doi.org/10.1021/acs.energyfuels.8b04508.

[16] S. Lawson, B. Adebayo, C. Robinson, Q. Al-Naddaf, A.A. Rownaghi, F. Rezaei, The effects of cell density and intrinsic porosity on structural properties and adsorption kinetics in 3D-printed zeolite monoliths, Chem. Eng. Sci. 218 (2020) 115564, https://doi.org/10.1016/j.ces.2020.115564.

[17] S.L. Taylor, A.E. Jakus, R.N. Shah, D.C. Dunand, Iron and nickel cellular structures by sintering of 3D-printed oxide or metallic particle inks, Adv. Eng. Mater. 19 (2017), https://doi.org/10.1002/adem.201600365.

[18] A.E. Jakus, S.L. Taylor, N.R. Geisendorfer, D.C. Dunand, R.N. Shah, Metallic architectures from 3D-printed powder-based liquid inks, Adv. Funct. Mater. 25 (45) (2015) 6985-6995, https://doi.org/10.1002/adfm.201503921.

[19] S. Wang, P. Bai, M. Sun, W. Liu, D. Li, W. Wu, W. Yan, J. Shang, J. Yu, Fabricating mechanically robust binder-free structured zeolites by 3D printing coupled with zeolite soldering: a superior configuration for CO2 capture, Adv. Sci. 6 (2019) 1-9, https://doi.org/10.1002/advs.201901317.

[20] A.I. Cernencu, A. Lungu, I.-C. Stancu, A. Serafim, E. Heggset, K. Syverud, H. Iovu, Bioinspired 3D printable pectin-nanocellulose ink formulations, Carbohydr. Polym. 220 (2019) 12-21, https://doi.org/10.1016/j.carbpol.2019.05.026.

[21] V. Vancauwenberghe, P. Verboven, J. Lammertyn, B. Nicolaï, Development of a coaxial extrusion deposition for 3D printing of customizable pectin-based food simulant, J. Food Eng. 225 (2018) 42-52, https://doi.org/10.1016/j. jfoodeng.2018.01.008.

[22] V. Vancauwenberghe, V. Baiye Mfortaw Mbong, E. Vanstreels, P. Verboven, J. Lammertyn, B. Nicolai, 3D printing of plant tissue for innovative food manufacturing: Encapsulation of alive plant cells into pectin based bio-ink, J. Food Eng. 263 (2019) 454-464, https://doi.org/10.1016/j.jfoodeng.2017.12.003.
[23] S. Sultan, A.P. Mathew, 3D printed scaffolds with gradient porosity based on a cellulose on a cellulose nanocrystal hydrogel, Nanoscale. 10 (2018) 4421-4431, https://doi.org/10.1039/c7nr08966j.

[24] Y. Jiang, J. Zhou, Z. Yang, D. Liu, X. Xv, G. Zhao, H. Shi, Q.i. Zhang, Dialdehyde cellulose nanocrystal/gelatin hydrogel optimized for 3D printing applications, J. Mater. Sci. 53 (16) (2018) 11883-11900, https://doi.org/10.1007/s10853-0182407-0.

[25] Y. Luo, Y. Li, X. Qin, Q. Wa, 3D printing of concentrated alginate/gelatin scaffolds with homogeneous nano apatite coating for bone tissue engineering, Mater. Des. 146 (2018) 12-19, https://doi.org/10.1016/j.matdes.2018.03.002.

[26] N.M. Musyoka, L. Petrik, E. Hums, Synthesis of zeolite A, X and P from a South African coal fly ash, Adv Mater Res. 512-515 (2012) 1757-1762. doi: 10.4028/ www.scientific.net/AMR.512-515.1757.

[27] M.J. Mukaba, A.E. Ameh, C.P. Eze, L.F. Petrik, Evaluation of modified fly ash based naa-zeolite: effect of crystallinity on $\mathrm{CO} 2$ adsorption capacity, Environ. Eng. Manag. J. 19 (2020) 475-483.

[28] J. Chen, L.S. Loo, K. Wang, An ideal absorbed solution theory (IAST) study of adsorption equilibria of binary mixtures of methane and ethane on a templated carbon, J. Chem. Eng. Data 56 (4) (2011) 1209-1212, https://doi.org/10.1021/ je101099c.

[29] M. Thommes, C. Morlay, R. Ahmad, J.P. Joly, Assessing surface chemistry and pore structure of active carbons by a combination of physisorption (H2O, Ar, N2, CO2), XPS and TPD-MS, Adsorption 17 (3) (2011) 653-661, https://doi.org/10.1007/ s10450-011-9360-4.

[30] P.I. Ravikovitch, A. Vishnyakov, R. Russo, A.V. Neimark, Unified approach to pore size characterization of microporous carbonaceous materials from $\mathrm{N} 2, \mathrm{Ar}$, and $\mathrm{CO} 2$ adsorption isotherms, Langmuir 16 (2000) 2311-2320, https://doi.org/10.1021/ la991011c.

[31] S. Lawson, A.A. Rownaghi, F. Rezaei, Carbon hollow fiber-supported metal-organic framework composites for gas adsorption, Energy Technol. 6 (4) (2018) 694-701, https://doi.org/10.1002/ente.201700657.

[32] S. Lawson, M. Snarzyk, D. Hanify, A.A. Rownaghi, F. Rezaei, Development of 3Dprinted polymer-MOF monoliths for CO2 adsorption, Ind Eng Chem Res. 59 (2020) 7151-7160, https://doi.org/10.1021/acs.iecr.9b05445.

[33] B.R. Pimentel, M.L. Jue, E. Zhou, R.J. Verploegh, J. Leisen, D.S. Sholl, R.P. Lively, Sorption and transport of vapors in ZIF-11: adsorption, diffusion, and linker flexibility, J. Phys. Chem. C 123 (2019) 12862-12870, https://doi.org/10.1021/ acs.jpcc.9b02192.

[34] S.C. Taylor-Lange, E.L. Lamon, K.A. Riding, M.C.G. Juenger, Calcined kaolinite-bentonite clay blends as supplementary cementitious materials, Appl. Clay Sci. 108 (2015) 84-93, https://doi.org/10.1016/j.clay.2015.01.025.

[35] F.M. Dardir, A.S. Mohamed, M.R. Abukhadra, E.A. Ahmed, M.F. Soliman, Cosmetic and pharmaceutical qualifications of Egyptian bentonite and its suitability as drug carrier for Praziquantel drug, Eur. J. Pharm. Sci. 115 (2018) 320-329, https://doi. org/10.1016/j.ejps.2018.01.041.

[36] R. Rodríguez-Rodríguez, Z.Y. García-Carvajal, I. Jiménez-Palomar, J.A. JiménezAvalos, H. Espinosa-Andrews, Development of gelatin/chitosan/PVA hydrogels: Thermal stability, water state, viscoelasticity, and cytotoxicity assays, J. Appl. Polym. Sci. 136 (10) (2019) 47149, https://doi.org/10.1002/app.47149.

[37] E.A.M.S. Almeida, S.P. Facchi, A.F. Martins, S. Nocchi, I.T.A. Schuquel, C V. Nakamura, A.F. Rubira, E.C. Muniz, Synthesis and characterization of pectin derivative with antitumor property against Caco-2 colon cancer cells, Carbohydr. Polym. 115 (2015) 139-145, https://doi.org/10.1016/j.carbpol.2014.08.085.

[38] Q. Al-Naddaf, S. Lawson, A.A. Rownaghi, F. Rezaei, Analysis of dynamic CO2 capture over $13 \mathrm{X}$ zeolite monoliths in the presence of SOx, NOx and humidity, AIChE J. (2020) 1-10, https://doi.org/10.1002/aic.16297.

[39] M. Thommes, K. Kaneko, A.V. Neimark, J.P. Olivier, F. Rodriguez-Reinoso, J. Rouquerol, K.S.W. Sing, Physisorption of gases, with special reference to the evaluation of surface area and pore size distribution (IUPAC Technical Report), Pure Appl. Chem. 87 (2015), https://doi.org/10.1515/pac-2014-1117.

[40] A.A. Ismail, R.M. Mohamed, I.A. Ibrahim, G. Kini, B. Koopman, Synthesis, optimization and characterization of zeolite A and its ion-exchange properties, Colloids Surf., A 366 (1-3) (2010) 80-87, https://doi.org/10.1016/j. colsurfa.2010.05.023.

[41] S. Couck, J. Cousin-Saint-Remi, S. Van der Perre, G.V. Baron, C. Minas, P. Ruch, J. F.M. Denayer, 3D-printed SAPO-34 monoliths for gas separation, Microporous Mesoporous Mater. 255 (2018) 185-191, https://doi.org/10.1016/j. micromeso. 2017.07.014.

[42] F. Magzoub, X. Li, S. Lawson, F. Rezaei, A.A. Rownaghi, 3D-printed HZSM-5 and 3D-HZM5@SAPO-34 structured monoliths with controlled acidity and porosity for conversion of methanol to dimethyl either, Fuel 280 (2020) 118628, https://doi. org /10.1016/j.fuel.2020.118628.

[43] Q. Almas, M.A. Naeem, M.A.S. Baldanza, J. Solomon, J.C. Kenvin, C.R. Müller, V. Teixeira da Silva, C.W. Jones, C. Sievers, Transformations of FCC catalysts and carbonaceous deposits during repeated reaction-regeneration cycles, Catal. Sci. Technol. 9 (24) (2019) 6977-6992, https://doi.org/10.1039/C9CY01680E.

[44] O. Cheung, N. Hedin, Zeolites and related sorbents with narrow pores for CO2 separation from flue gas, RSC Adv. 4 (2014) 14480-14494, https://doi.org/ 10.1039/c3ra48052f. 